\title{
Nature-related experience. Response to the questionnaire concerning human experience associated with nature*
}

\section{Henryk Elzenberg}

After a thorough review of the material, I have decided to give my response following an order of my own choosing. Nevertheless, all questions shall be answered at appropriate junctures in the text, by means of relevant references.

\section{Introductory remarks}

\section{(Questions: 1, 3, 5, 7, 16)}

I count myself among who are sensitive to nature and respond to it (question 1). My inner experience of nature is strong and occupies one of the foremost places among my experiences in life (question 7).

As for my attitude to the countryside, the matter stands as follows. The periods spent in the countryside (question 5) amount to a total of 10 years, that is more or less one-sixth of my lifetime so far. This includes-certainly countryside-like for the purposes of this questionnaire-the stays in Zakopane, some 2 years altogether, and the several months spent at the front in 1915. For the most part, those sojourns qualified as holiday time. The following periods, however, were not vacations: 1) I spent two years of regular school education between the ages of 13 and 15 in the village of Trogenin, Switzerland, as a resident of the boarding house there (leaving for the city during holidays); 2) on two occasions (in 1906 and 1918) I spent a part of the summer as a holiday-time tutor in private houses in the countryside; 3 ) during the schoolyear of 1917/18, I worked for seven months as a teacher at a grammar school in Zakopane; 4) beginning in 1921, I taught several times at various summer courses at the seaside or in mountainous areas-some two months in

This translation is based on Elzenberg's article "Nature-Related Experience" (1969) that was Elzenberg's response to a survey on the topic of experience of nature. 
total, or a little more; 5) many times, especially in later years, I would retreat to the countryside to write or do scholarly work, sometimes combining leisure and work; there were over a dozen of such stays, each lasting three to four weeks on average; 6) despite spells of blissful idleness, the stay at the front cannot be wholly considered to have been leisure. It was then (question 16) - for the only time in my life-that I had my taste of genuinely hard physical labour. I had, often in scorching heat, to dig ditches, carry large logs, lift hedgehogs etc. As I was recovering from utter exhaustion and, not infrequently, a feeling of being maltreated, nature may have been a soothing factor to a degree, drawing me back into a world of subtler experience. Still, I communed with it more intensely in periods that were free of tiredness, particularly in the moments of general relaxation when we felt less involved in the activities of warfare.

Based on such experience of living in the countryside and my thorough knowledge of life in varied cities-from Paris to Piotrków Trybunalski-I will now answer question 3: I feel better in the countryside and it is there that I would like to live. Naturally, this is a brief answer. There would be two reservations here: one, usually expressed in such situations, regarding the possibility of unconstrained travels to the city in order to "satisfy cultural needs" (although I do not know what I would do if I were categorically denied such possibilities!); second, concerning certain cities which in a sense include so much of the countryside as to combine the advantages of both. I know those to exist in Switzerland for instance, and I have always passionately longed for the conditions I came to know there.

\section{Limitations of the notion of "nature-related experience"}

The questionnaire does not exactly define the concept of "nature-related experience"; yet, by virtue of the alternatives it uses on several occasions, namely "experience of nature" and "communing with nature" it appears-to a certain degreeto anticipate my own understanding of the matter. Still, for the sake of accuracy, I would like to note that "nature-related experience" with the meaning I find particularly interesting, does not include the intensely physical experience associated with marching, healthy tiredness, wind, sun, the fresh air itself etc. Nor do I classify adventure-like experience, struggles with the elements, or possibly danger (in the mountains, on the waters) as such. Although I have always been highly sensitive to all those experiences and held them in high regard as they were a source of physical and moral fortitude, in the end I found them to belong rather to a biological, and therefor inferior sphere, one which constitutes only a substratum for "life" proper. Hence, what I refer to here as "nature-related experience", means in all instances an experience whose character is more or less "contemplative". And another thing: I consider my otherwise warm-hearted sentiment towards animals and a proclivity for observing their lives to be an utterly separate domain, which 
is not "experiencing nature" in the sense in which I construe it. The transition from "contemplating nature" to watching a squirrel—though it may proceed seamlesslyrepresents in my opinion an absolute shift from one sphere of reality and one attitude into another sphere and another attitude. What follows will clarify that.

\section{The initial realization of the need to commune with nature}

\section{(Question 6)}

When I was barely eight years old and was staying during the summer in Czarniecka Góra near Niekłań, I was allowed for a time to ride the very nice pony stabled there; riding on its back I would once or twice venture into the woods. I remember the extraordinary delight I took in those jaunts, and even today I feel thoroughly in accord with myself as I was then in the appraisal of that pleasure. When the permission was later withdrawn, I felt something was terribly lacking. Whether this was the need to commune with nature is difficult to say. There is no doubt that my passion for the horse took precedence, but the charm of riding in the woods surpassed the charm of horseback excursions anywhere else, and I rued the loss.

The second stage-if the above is considered the first-came with my penchant for seeking free nature in which to read books, especially poetry, a predilection that developed only at the age of 14 or 15 . The need for poetry, of which I had been aware since childhood, was a strong one, and at that time I began to feel that those two things are in some way connected.

However, the acute and conscious need for nature for nature's sake emerged, as far as I can say, around the age of 17 . When I was 17 , I would write poems about nature, pieces in which I was very involved emotionally (NB without any amorous component and any detectable relation to eroticism whatsoever). There are a number of remarks to be made concerning the external stimuli which may have had an effect there, yet it would be more appropriate to do so later.

\section{Early stages of the natural experience}

\section{(Question 8 as well as 12 and 15)}

I shall now address another biographical question, namely question no. 8, regarding the evolution of my attitude to nature. I will attempt to answer this question in successive parts since in a simplified perspective it appears that in the course of my life my feeling for nature went only through three major phases; however, if they are examined in detail, I can see that the picture is far more complex. So for now, I will try in this section to characterize the two earliest stages which demonstrate sufficient distinctiveness. The last phase, lasting from mature adulthood until today, is equally distinct. In the middle (early adulthood) there is a definitely more obscure period in which various threads are interwoven. 
The two first phases may be defined as follows: the first was "purely aesthetic"1; the second was "lyrical" or "poetic" and, approached from a slightly different angleit could be deemed a "literary" stage. I should mention that I do not perceive the changes I am about to describe as the mere substitution of certain spiritual attitudes by others, but as the emergence of new elements which gain ascendancy; at the same time, the old elements-at least some of them-endure, becoming integrated into more complex wholes.

The first, truly powerfully contemplative experience of nature I can recall were the so-called Alpenglühen in the Bernese Alps, seen from the terrace of the Victoria Hotel in Interlaken. I was 9, no more, no less. Alpenglühen, as we know (at this point I am trying, to the best of my ability, to answer the first part of question 15), may be seen at sundown when, in propitious atmospheric conditions, the snow-capped peaks "light up"-passing gradually from the subtlest of pinks to the most incandescent purple, after which they fade gradually as well, showing a different spectrum which no longer dwindles back to pink but to ever paler gold. It is a tremendous crescendo succeeded by a decrescendo of luminescence and fire, quite symphonic in a way, where the magnificence of the picture is also affected by the distance from the viewer (not too close and not too far either), the absolute (sufficiently extensive) dimensions of the snow-covered fields and the very relief of the peaks (not too pointed, not too rounded). In that respect, the conditions in Interlaken are splendid, and that evening the symphony was played in as classical a fashion as it could be. A phenomenon that perfect (I have already mentioned that auspicious weather conditions are indispensable) is relatively rare, and I do not recall having watched it later in an equally flawless form-at any rate that first impression surpasses all later ones in my memory. The impression was forceful, and the rapture was immense; I also remember some of the circumstances which accompanied it. As for my subjective response (here I am moving on to the characterization of that earliest phase), I can recall little of it; in no case did this experience bore down to the level of feeling, though these did exist and had been reached much earlier by the experience relating to poetry. This was merely a magnificent view and only admiration. For many years, my reactions to nature continued in that vein, fostered by my continuous stay in Switzerland, whose landscapes are replete with outward opulence. So I choose to refer to that stage as "purely aesthetic". Let me just add that the beauty of nature experienced in this manner, regardless of how open and sensitive I was to the experience, had not played such a role in my life as it did later, having acquired a "soul".

After a kind of "prelude" discussed in the preceding paragraph, a new approach to nature manifested itself, as I began to experience nature's vistas as aspects of

1 The use of this word here may be inappropriate-at any rate it is employed in a very narrow sense. One should perhaps say "aesthetic in the purely sensory meaning", "aspectual", or "external". After all, all phases until the end have been aesthetic in the proper sense of the word. 
the cosmos, while seeing their external beauty either as an embodiment of those powers or as a dominant contrast to the terror of reality. This was because at the time-I had just turned 16, which I remember precisely-I entered into a period of acute pessimism with underlying thoughts of death and transience. This new attitude went hand in hand with a new mode of responding, what I referred to previously as "poetic" or "lyrical". Rather than direct aesthetic shock, I began to appreciate nature's reverberations and continuities in my inner life, the states of elation or melancholy incited by nature. I gave this experience a poetic form.

However, though that phase may also be called a "literary" one, I did not mean to exploit the experience of nature as creative "raw material" for the art of writing. I would understand the term as denoting several, quite distinct other things that I enumerate below:

A. Not contenting oneself with feelings which arose spontaneously as a result of communing with nature but s e e king them consciously; p r o vi d in g them to oneself in a sense, and, if they failed to come unprompted, s u g g e s $\mathrm{t}$ in $\mathrm{g}$ them to oneself, not without some artificiality at times. This would be the "literariness" in the negative sense: that artificiality which in certain cases led to insincerity. Once, barely 18 years old, I stayed overnight in a hostel high in the Alps, and I sneaked out in the middle of the night to see the landscape I knew by day but now could see in the light of the moon. I remember quite clearly that I was looking for some peculiar, unknown thrills. I became greatly annoyed when they failed to materialize, and the object which shone most beautifully in that lunar glow turned out to be an empty tin of sardines. Still, occurrences of this kind were chiefly a thing of the earliest moments of that phase: at around 17, 18, up to 19 years of age. Subsequently, a certain equilibrium established itself: I knew what to expect in communing with nature, and that satisfied me entirely.

B. Associating views of nature with literary recollections (of poets for the most part, of course) and assembling them into wholes or superordinate collectionscreatively to a degree-whose beauty relied on two kinds of distinct elements (such as words and music in a song, motion and music in a dance). The most beautiful was the vision I had during an excursion in the environs of Neuchâtel in Switzerland; I was nearing my $24^{\text {th }}$ birthday at the time. Standing atop a hill I had a view of three lakes which shone half dark, half red gold in the sunset. I immediately apprehended the entire surroundings as a tremendous, mythological battlefield, where the lakes were the shields of Homerian gods, discarded before departing into the sky following the fight.

The example is a typical one; at the time, I even deeply considered the thoughtwhich crystallized under the influence of a phrase from Goethe's Italian Journey (1982) - that poetry, fusing with nature in that fashion, "ennobles" it (as Goethe put it). (This point appears to me to provide a partial answer to question 12 as well. 
Moreover, I would like to make two marginal remarks here, for which I can see no appropriate place elsewhere).

1. Not only in the aforementioned instance-but on many occasions in fact-I happened to mythologize nature (in the Greek spirit), in a manner that was very natural and spontaneous. In particular at that age-namely at 23, 24 and older-my imagination was imbued with Greek poetry most thoroughly. Nonetheless I can recall a vivid and unmitigated example of mythologization from the period after I reached 42.

2. In some rare instances, the experience of nature did not combine into a superior whole with poetry but with music instead. In the case which proved most momentous for the spiritual development it was Wagner (I was 23 or 24 years of age).

C. I will now address the third point relating to the "literariness" of the discussed phase. Even today I find it problematic to determine the extent to which that awakening of the "lyrical" or "poetic" response to nature was extemporaneous and how far it was influenced by poets, especially French Romantics and Post-Romantics read towards the end of my grammar school years. They did indeed have some share in it they did indeed; how much there was of it should resolve whether those reactions of mine should be deemed "literary" also in genetic terms. While I make note of it for the sake of the accuracy of the picture, I do not wish to imply that the literary impulse was the principal one-it seems rather that on closer scrutiny I would be able to demonstrate a certain intrinsic continuity of development.

\section{The transitional phase}

\section{(Question 8, continued; in part also-questions 12 and 10)}

The designation "transitional" is utterly inappropriate; after all this is the longest phase, spanning at least twenty years, a quarter of a century, perhaps. Yet I do not have a better epithet, since even my own understanding of the matter is exceptionally imperfect here. While providing what I am capable of at this point, I shall distinguish between two aspects of the matter.

Firstly, from a certain perspective, the phase could be called "metaphysical". The cosmic approach to views of nature grows ever stronger: each sight is treated abstractly or as representative of cosmos and as such elicits a particular emotional response, depending in the ontological vision which manifest itself at the given moment. Within such a frame of reference, one phenomenon in particular rose to the fore (most strikingly with respect to seascapes): a full and lively animation followed by violent and almost brutal shift into an acutely materialistic and mechanistic vision: "All that ostensible, enormous life is in fact no more than the movement of particles; I stand as the sole living witness facing a thoroughly dead world", and the naturally emotional further sequences of such reflections. 
This mode of construing things was particularly forceful somewhere around the age of 34 and after, only to abate substantially after forty.

Secondly, however-not so much in terms of the interpretation of sights but the very attitude adopted - the phase may be referred to as a stage of "an ever greater and more profound contemplativeness". The need for a focused, possibly immobile and perfectly undisturbed prolongation of the communion with nature intensifies. These states are increasingly felt as states of "detachment from the world" (the "ordinary" world), and immersion into "another world" which is also more and more often contrasted as "better" with the former, more or less "bad" one. What I understood as the "ordinary world" I have never been able to formulate in thought, despite repeated attempts. It was only very late and with hesitation that I dared to think that it was simply the world of socially organized human co-existence. "La societe, c'est le mal". Still, this is probably only a part of the truth.

Compounded by the latter process, the role of the experience of nature grew continually more important. It gradually ceased to be "a luxury item" or splendour in life, becoming indispensable for that life to be sustained. At the same, and in partial answer to question 10, the grandeur and excellence of landscape proved less and less needed, whereas a predilection for unpretentious, intimate scenery gained in strength. I recall having had the first powerful reactions to evidently modest views at the age of around 25 or 26 ; later, this became a matter of course.

\section{My reception of nature in its crystallized, final form}

\section{(Question 13, as well as question 12)}

Calling it a "final" form is probably justified because nothing but regressions are objectively possible at this juncture. At any rate, this is how I subjectively perceive it, given that it has solidly crystallized and only in this particular variant has the experience of nature become firmly and consciously integrated into the entirety of what admittedly is not a "worldview" but should perhaps be generally called a "personal attitude towards the world". I would be inclined to refer to that phase using a term that I otherwise employ as a technical one: I shall call it a "paramystical" phase (why not directly mystical will become sufficiently apparent in the course of the description). The phase had its powerful "prelude" in the aforementioned experience involving Wagner's music (section IV). I arrived at its threshold borne by "deepening contemplativeness" and by "turning away from the world" in the transitional phase - three processes I have just discussed. The boundaries here would have been quite fluid, had it not been for a singular impulse from the outside which deserves to be recalled. In a study on the religions of China, I found a mention stating more or less that Taoists (yes!!) practiced communing with nature as an element of mystic life. Then, quite suddenly, I realized that the aspirations inherent in my experience of nature are akin. Regrettably, I cannot provide 
the exact date; it could not have happened prior to 1937 and later than in the first months of the war. Therefore, I must have been between 50 and 52. The realization had an undoubted impact on the later conscious interpretations of my experience of nature. It remains an open question as to whether and to what an extent the interpretation affected the experience itself.

Let me then embark on an analysis. To make this exceedingly difficult task easier, I will begin with negative statements. First and foremost (here follows the subsequent part of the answer to question 12), my experience of nature has never involved a response of a theistic kind. Never, from my childhood days till now, have I thought of nature as the "work of the Creator" or discern the so-called "divine presence" in it. Nor have I experienced this in the pantheistic sense, even in a loose, noncommittal sense. In general, alien to me is one of the most classic types of experiencing nature: that sense of being incorporated into nature, dissolving in it, losing oneself while forsaking one's own individuality and distinctiveness. It is always quite the opposite with me. I experience nature as something utterly external, and experience myself as a pure subject, a thinking and feeling mirror. So my attitude to nature is "contemplative" in a robust and strictly defined meaning of the word. In a figurative sense, we could say that I sense the visible unfolding in front of me to be two-dimensional. In the literal sense, this would be evidently untrue-as I will repeat later the dimension of depth plays a particular role. Still, the metaphor as a metaphor suggests itself to me almost irresistibly. Visible reality has no "depth" of its own in some ontological, metaphysical sense. It is a great veil, something made of gauze, a patterned yet see-through fabric hanging before the onlooker.

The fabric has to be beautiful to the senses; there is no experience without it. Nonetheless, its foremost role is that the images and shapes embroidered on it are experienced as aspects, externalizations, symbols of the reality concealed beyond the veil. Meta-empirical reality, experienced via the ordinary routes as unattainable and non-cognizable, indeterminable to intellectual and sensory facilities, becomes accessible and close-and in an attenuated sense seemingly cognizable and perhaps even (?) definite-through symbols which the landscape supplies.

It is for that reason that I have just spoken of things being "see-through": here, nature is the veil, the stretch of gauze through which the meta-nature shows. The latter, obviously, does possess a depth.

This mode of experience entails another negative characteristic: in general, the awareness that the plant life which the landscape comprises is a live in the biological sense appears to play a negligible role. It resurfaces only when "establishing a personal relationship" with an individual plant, being in part a foundation of powerful personification at that point. With respect to the contemplated nature that is approached in its entirety, it is likely not to exist at all; the "life" of trees, flowers and fields is in their very symbolism, in the meta-empirical breath wafting within; essentially, it does not differ from the "life" of waves or clouds. In this 
matter, however, certain tonalities and distinctions should be taken into account, and it is not lucid to me at all; it is only the most general tendency that I do not doubt.

\section{The outcomes of contemplating nature}

\section{(Question 11)}

I can hardly claim anything about the inner "changes"-meaning permanent ones, of course-that are due to the influence of nature; the latter becomes lost somehow in the deluge of other influences. It is rather evident and clear that it is the mode of experiencing nature which changes with the person, notably with the worldview and the general attitude to the world. On the other hand, certain processes mentioned in the description of the "transitional phase" are a doubtful upshot of life's affairs and vicissitudes: the exhaustion of the conquering spirit of youth, the sufferings one has been through, becoming discouraged with the humankind and one's own human nature.

"What does communing with nature give me"? At the pinnacles of such experience it has always given me a complete and perfect sense of happiness, with a hue I will attempt to define thus: grand aspiration and elation in the youthful phase, rather soothing tranquillity in the middle phase, and a sense of completion in the final one. However, at times things tended to be quite otherwise. The feeling of being fortified and cheered up within, which lasted for some time afterwards, need not be mentioned I guess. The essence of things is more profound still, and in spite of sincere willingness to do so, I find a thorough answer difficult. "Shaking off all the realities and liberation": this is perhaps one of the viable formulas. Liberation from what? To a fair measure from the crushing burden of social bonds. Obviously, from the practical constraint and being geared towards the practical, though this is a truism. A little deeper perhaps: from the world of "things" into which the "practical reality" has been cut up and portioned. It is that somewhat mysterious liberation that I seek in nature and in music. Finally, not to overlook a certain important observation which by no means pertains to the description of the experience of nature, but to the consistent attempts at integrating that experience into an orderly hierarchy of all life's pursuits, I would advance, not without hesitation, the following formula: aside from other important ways, communing with nature is one of the paths on which I strive to overcome the sense phenomenality of my own reality. This is already vague language, being no more and no less than... "paramystical". 


\section{Communing with nature and relationships with people}

\section{(Questions 9 and 14)}

The fullness of communing with nature is possible for me solely in absolute and unqualified solitude. On a lonely excursion, as long as I am not bound by a strictly defined route, I steer clear of places of habitation, even persons I chance to notice from afar. Within reasonable bounds, I prefer to stray rather than ask the way, suffer thirst rather than enter a dwelling. The degree of that obstinacy towards lonesomeness tended to vary, being very high during the last war, and it is chiefly the latter reminiscence that makes me note the fact. Conversely, when I am in company, I routinely and deliberately "switch off" (as one does with electricity) my deeper sensibility to nature, allowing myself-at the most-reactions which are "purely aesthetic" (in the sense adopted in this disquisition) and fairly superficial at that. Only a very close emotional rapport with my companion might change something about the situation, still peak experience remains beyond reach.

By and large, I do not speak of my experience regarding nature. If it does nevertheless happen, I speak untruthfully while maintaining the pretence of verity: I give a shell (a matter-of-fact account of the visual aspect with an occasional formula intimating the mood), while keeping the heart of the matter to myself. This does not seem to result exclusively from familiar psychological traits of a "schizothymic" or "introverted" individual etc. Another, altogether reasonable cause is the awareness of the utter inability to describe the essence of things with language other than artistic language.

\section{Supplement}

\section{(Questions 10, 15, 17)}

This section comprises answers and fragments of answers for which no suitable place could be found in the previous sections.

Question 10-a penchant for specific landscapes. I may have some slight predilection for the sea; to a lesser degree, for other expanses of water in general. Apart from that, a distant, unimpeded horizon, open in one or two (not all!) directions appears to foster the fullness of experience. I do need such landscapes from time to time, to the extent that missing these may cause the need to become a craving; however, once I have obtained an adequate "supply" of this kind of encounter, I can then get by for longer spells with circumscribed landscapes too. As for "splendid" and "modest" landscapes, I have addressed those above.

Question 15-the most recent experience. My most recent, strong experience of nature dates probably to October last year (1946). No more than twenty kilometres outside Torun I discovered a stretch of land which astonished me with its "tart" wildness and absence of any traces of cultivation. The area was extremely irregular: 
half of it heath, half grassland, high-growing, dry and rustling; birches and other slender trees, isolated or in groups, all leaning towards one side, bent by the western winds; incredible, austere and vivid colour effects, though at the same time seldom opulent and singularly subdued by autumn; a cloudy day; wind above it all; a mood for whose description I have already introduced the word "tart"-which I use with the intention of praising. The experience was powerful, even if it was not complete. I did not reach the fullness of experience due to many mundane worries. The last complete experience I enjoyed came about as far away as Vilnius-between 1942 and 1944. In this period, I enjoyed an abundance of experiences of this kind; it was the peak period of my communing with nature. No later than in June 1944, the most potent experience I have ever enjoyed took place; it was west of the city, somewhere further down the valley of the Vilnius river at whose broad bend I was looking, sitting or lying on a hill under the eaves of young trees-what trees they were I cannot recall. Thus it was that probably for the very last time I experienced my act of "liberation". As it had happened more than once in my youth, that afternoon the image of nature coalesced in my mind with the thought of death. On this occasion, however, the tenor of it was rather exceptionally enthusiastic.

Question 17-dreams. After all I have said, here is an astonishing thing: nature hardly ever makes an appearance in my dreams. I dream quite a lot as a rule and manage to retain many of my dreams in memory. Nonetheless, one or two beautiful seascapes are virtually all that I can recall with any reasonable clarity. In the particularly memorable dreams there was once only a garden and swaying trees as a backdrop to a perfectly serene love scene. The hand of a woman dressed in white rose to a low-hanging branch, which curved in a beautiful, pure arc above her head. I well remember the garden and the branch (I was 26 then); they constituted an image of perfect harmony.

\section{Appendix: on other persons}

\section{(Questions 18 and 19)}

Regrettably, there is nothing I can say about children (question 19). As for rural persons (question 18), I will only provide two details-not particularly interestingfor the sake of contrast. A certain young servant in Warsaw, a person originating from the countryside where she had been born to a family of Polonized German colonists (name of Józefa Wagner), a very cultured girl, told me that she would always look forward with longing to holiday stays in her home country, not least because of their beauty. The exact phrase she used was: "one can never have enough of that beauty." Then, journeying once in the Western Tatra mountains, at the feet of the Wołowiec, I came across a middle-aged highlander, whom I asked about the way. He showed it to me fairly contemptuously, and he accentuated his viewpoint thus: 
Henryk Elzenberg

"Wołowiec is nowt of wonder to me. It's mayhap five score times I've been up there with my sheep."

\section{Bibliography:}

Elzenberg, Henryk. (1969). Nature-Related Experience. Znak, 1969, no.181-182, pp. 984-996.

Goethe, Johann Wolfgang. (1982). Italian Journey, translated by W. H. Auden and Elizabeth Mayer. London: Penguin Books. 